\title{
Oxidative damage and brain concentrations of free amino acid in chicks exposed to high ambient temperature
}

\author{
Vishwajit S. Chowdhury $^{\mathrm{a}, *}$, Shozo Tomonaga ${ }^{\mathrm{b}, 1}$, Taro Ikegami ${ }^{\mathrm{b}, 2}$, Edi Erwan ${ }^{\mathrm{b}}$, Kentaro Ito ${ }^{\mathrm{b}}$, \\ John F. Cockrem ${ }^{c}$, Mitsuhiro Furuse ${ }^{\text {b }}$ \\ a Division for Arts and Science, Faculty of Arts and Science, Kyushu University, Fukuoka 819-0395, Japan \\ ${ }^{\mathrm{b}}$ Laboratory of Regulation in Metabolism and Behavior, Faculty of Agriculture, Kyushu University, Fukuoka 812-8581, Japan \\ c Institute for Veterinary, Animal and Biomedical Sciences, Massey University, Palmerston North, New Zealand
}

\section{A R T I C L E I N F O}

\section{Article history:}

Received 13 October 2013

Received in revised form 16 December 2013

Accepted 27 December 2013

Available online 31 December 2013

\section{Keywords:}

Brain

Oxidative damage

Free amino acids

Food intake

High ambient temperature

Chick

\begin{abstract}
A B S T R A C T
High ambient temperatures (HT) reduce food intake and body weight in young chickens, and HT can cause increased expression of hypothalamic neuropeptides. The mechanisms by which HT act, and the effects of HT on cellular homeostasis in the brain, are however not well understood. In the current study lipid peroxidation and amino acid metabolism were measured in the brains of $14 \mathrm{~d}$ old chicks exposed to HT ( $35^{\circ} \mathrm{C}$ for $24-$ or 48 -h) or to control thermoneutral temperature $\left(\mathrm{CT} ; 30^{\circ} \mathrm{C}\right)$. Malondialdehyde (MDA) was measured in the brain to determine the degree of oxidative damage. HT increased body temperature and reduced food intake and body weight gain. HT also increased diencephalic oxidative damage after $48 \mathrm{~h}$, and altered some free amino acid concentrations in the diencephalon. Diencephalic MDA concentrations were increased by HT and time, with the effect of HT more prominent with increasing time. HT altered cystathionine, serine, tyrosine and isoleucine concentrations. Cystathionine was lower in HT birds compared with CT birds at $24 \mathrm{~h}$, whilst serine, tyrosine and isoleucine were higher at $48 \mathrm{~h}$ in HT birds. An increase in oxidative damage and alterations in amino acid concentrations in the diencephalon may contribute to the physiological, behavioral and thermoregulatory responses of heat-exposed chicks.
\end{abstract}

(c) 2013 Elsevier Inc. All rights reserved.

\section{Introduction}

High ambient temperature (HT) can decrease food intake, live weight gain, and food efficiency in broilers (Howlider and Rose, 1987; Siegel, 1995; Niu et al., 2009; Azad et al., 2010a), and can affect egg production in laying hens (Marsden et al., 1987; Peguri and Coon, 1991; Yahav et al., 2000; Sterling et al., 2003; Lin et al., 2004; FrancoJimenez and Beck, 2007; Ajakaiye et al., 2010). The exposure of birds to HT can lead to an increase in deep body temperature (rectal temperature; Yahav and Hurwitz, 1996; Chowdhury et al., 2012a,b) and may cause heat stress (Bartlett and Smith, 2003; Soleimani et al., 2010). It is thought that the negative effects of heat stress on growth rate and production are probably due to reduced food intake in birds (Hurwitz et al., 1980; Savory, 1986), and food consumption, growth rate, food efficiency and survivability all decline in poultry as environmental temperature increases (Mashaly et al., 2004; Yu et al., 2008).

\footnotetext{
* Corresponding author. Tel.: + 8192642 2954; fax: +8192642 3098

E-mail address: vc-sur@artsci.kyushu-u.ac.jp (V.S. Chowdhury).

1 Shozo Tomonaga is now at the Laboratory of Nutritional Science for Animals, Graduate School of Agriculture, Kyoto University, Kyoto, 606-8502, Japan.

2 Taro Ikegami is now at the Department of Chemistry, Biology and Marine Science, University of the Ryukyus, Okinawa 903-0213, Japan.
}

Behavioral, physiological and molecular adjustments occur during heat stress (Etches et al., 1995; Chowdhury et al., 2012a), and heat stress is one of the major causes of oxidative stress. Oxidative stress is defined as an imbalance of pro-oxidants and antioxidants, or a disruption of redox signaling and control (Lin et al., 2000; Jones, 2006; Lin et al., 2006; Azad et al., 2010b). HT can also have adverse effects on the structure and physiology of cells, and can impair transcription, RNA processing, translation and oxidative metabolism, as well as cause disruption of membrane structure and function (Iwagami, 1996; Mujahid et al., 2009; Azad et al., 2010b). Oxidative deterioration or peroxidation of cellular membrane lipids has been suggested as forming part of the cellular ageing process and to contribute to several age-associated degenerative diseases and various pathological conditions (Bast and Goris, 1989). Lipid peroxidation is initiated following the abstraction of hydrogen from polyunsaturated fatty acids by hydroxyl radicals generated from hydrogen peroxide (Bhuyan et al., 1986), and lipid peroxidation plays a role in the disruption of the normal structure of membrane phospholipids. Malondialdehyde (MDA) is a major breakdown product of lipid peroxidases, and MDA concentrations have been used to assess lipid peroxidation. The thiobarbituric acid test for MDA is widely used as an indicator of lipid peroxidation (Satoh, 1978; Yagi, 1984; Likidlilid et al., 2010; Bhutia et al., 2011). Changes in cellular physiology during HT in poultry are not well known. Recently, it was reported that HT 
increased the concentrations of some hypothalamic neuropeptides in young chicks (Chowdhury et al., 2012a). Lipid peroxidation can occur during HT, and thus the first goal of this study was to measure MDA levels to determine whether HT alters lipid peroxidation in the chick brain.

The administration of various amino acids may reduce the effects of psychological and physiological stress in chicks (Yamane et al., 2009; Hamasu et al., 2010; Erwan et al., 2012). Hamasu et al. (2009) reported that L-proline and L-arginine were decreased in the telencephalon and diencephalon of chicks under isolation or fasting stress, and L-proline attenuated the stress response in the central nervous system of chicks. However, to our knowledge, changes of free amino acids in the chicken brain have not been measured during HT. Therefore, the second aim of this study was to analyze the changes of free amino acids in the diencephalon and plasma of heat-exposed chicks.

\section{Materials and methods}

\subsection{Animals}

Day-old male layer chicks (Julia strain; Gallus gallus domesticus) were purchased from a local hatchery (Murata hatchery, Fukuoka, Japan) and housed in groups in metal cages at a constant temperature of $30 \pm 1{ }^{\circ} \mathrm{C}$ under continuous light until 14 days of age. Food (Commercial starter diet (energy: $3050 \mathrm{kcal} / \mathrm{kg}$ and protein: 24\%); Toyohashi Feed and Mills Co. Ltd., Aichi, Japan) and water were available ad libitum. On the basis of a preliminary experiment, 14- or 21-day chicks were more responsive to HT in terms of food intake than neonatal chicks (Chowdhury et al., 2012b). Thus, we used 14-day old chicks to examine the effect of HT $\left(35^{\circ} \mathrm{C}\right)$ compared with a control thermoneutral temperature $\left(\mathrm{CT} ; 30^{\circ} \mathrm{C}\right)$ in this study. Chicks were placed in individual cages $12 \mathrm{~h}$ before starting the experiment. Twenty-eight chicks ( $n=14$ in each group) were exposed to HT or CT for 24- or 48-h, with chicks allocated to groups according to body mass so the initial body masses (average $146 \pm 1.5 \mathrm{~g}$ ) were similar in the two groups. Chicks were given free access to water and feed during exposure to HT or CT. This study was performed according to the guidance for Animal Experiments in the Faculty of Agriculture of Kyushu University and the Law (No. 105) and Notification (No. 6) of the Japanese Government.

\subsection{Experimental design}

Body mass and rectal temperature were recorded immediately before the HT chicks were placed in their cages into a temperaturecontrolled chamber (Sanyo Electric Co. Ltd., Japan), whilst control chicks were placed in their cages on similar racks in CT as per the method described previously (Chowdhury et al., 2012a,b). Rectal temperature, food intake and body mass were measured after 24- or 48-h of HT or $\mathrm{CT}$, after which birds were killed by exposure to anesthesia (isoflurane, Mylan Inc., Tokyo, Japan).

Brains were dissected (as shown in Fig. 1) and the diencephalon (thalamus and hypothalamus), telencephalon, mesencephalon and cerebellum collected and snap frozen for analyzing oxidative damage. The food intake of each bird during the treatment period was recorded by subtracting the weight of feed remaining in the feeder from the initial or initial plus added food during the 24- or 48-h experimental period. Adequate precautions were taken against food spillage, namely, food was provided up to the half of the feeders and the opening of the feeders was adequate for the chicks to feed without spillage of food. Rectal temperatures of chicks were measured using a digital thermometer with an accuracy of $\pm 0.1{ }^{\circ} \mathrm{C}$ (Thermalert TH-5, Physitemp Instruments Inc., USA), by inserting the thermistor probe in the cloaca to a depth of $1-2 \mathrm{~cm}$. Diencephalons were also collected from chicks maintained under identical HT conditions to the first experiment for 24- or 48-h of HT, and at the same time diencephalons were collected from control chicks. Randomly selected diencephalons from 24- and 48- h experimental and control groups ( $n=7$ in each group) were used for the analysis of free amino acid concentrations.

\subsection{Brain tissue MDA}

Brain tissues (diencephalon, telencephalon, mesencephalon and cerebellum) were used for MDA measurements. Tissues were homogenized in buffer $(100 \mathrm{mM} \mathrm{KCl}, 50 \mathrm{mM}$ Tris- $\mathrm{HCl}$ and $2 \mathrm{mM}$ ethyleneglycol tetraacetic acid, $\mathrm{pH}$ 7.4) for $1 \mathrm{~min}$ and then sonication for $15 \mathrm{~s}$ was performed. The homogenates were centrifuged at $700 \mathrm{~g}$ for $10 \mathrm{~min}$ and supernatants were collected. A Thiobarbituric Acid Reactive Substance (TBARS) assay kit (Cayman Chemical Company, Ann Arbor, MI, USA) was used for assaying lipid peroxidation in the brain tissue. Briefly, tissue homogenates were mixed with the supplied sodium dodecyl sulfate solution then a color reagent (thiobarbituric acid (TBA), diluted TBA acidic acid solution, diluted TBA sodium hydroxide solution) was prepared as per the manufacturer's protocol and added to the homogenates. After vortexing, samples were placed on vigorously boiled water for an hour. After one hour vials were removed and placed in an ice bath for $10 \mathrm{~min}$ to stop the reaction. After $10 \mathrm{~min}$, the vials were centrifuged at $1600 \mathrm{~g}$ at $4{ }^{\circ} \mathrm{C}$ for $10 \mathrm{~min}$. Vials were stable with pink color solution at room temperature for around $30 \mathrm{~min}$. Absorbance of the supernatant was measured at $562 \mathrm{~nm}$. The content of TBARS is expressed as the MDA equivalent. The protein content of tissue homogenates was

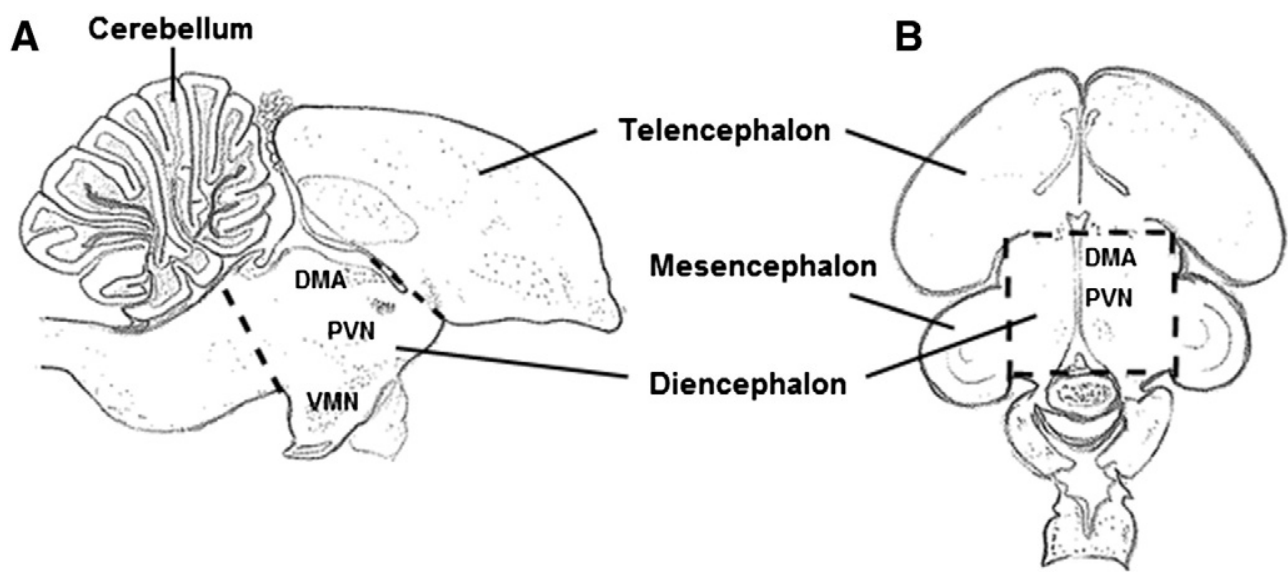

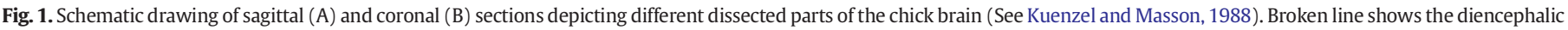

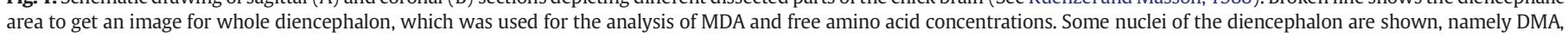
dorsomedial anterior nucleus; PVN, paraventricular nucleus; VMN, entromedial nicleus. 
determined by a bicinchoninic acid assay with bovine serum albumin as the standard and MDA contents were expressed as per mg protein. The samples were analyzed after no more than 1 week of storage at $-80^{\circ} \mathrm{C}$.

\subsection{Analysis of amino acids in the brain and plasma}

Free amino acid concentrations in brain were analyzed by HPLC according to the method of Boogers et al. (2008) with some modifications. Diencephalons were homogenized in ice-cold $0.2 \mathrm{M}$ perchloric acid solution containing $0.01 \mathrm{mM}$ ethylenediaminetetraacetic acid disodium salt (EDTA-2Na) and left on ice for deproteinization. After $30 \mathrm{~min}$ the homogenates were centrifuged at $0{ }^{\circ} \mathrm{C}$ and $20,000 \mathrm{~g}$ for $15 \mathrm{~min}$. Supernatants were collected and adjusted to $\mathrm{pH} 7$ with $1 \mathrm{M} \mathrm{NaOH}$. Plasma was prepared by centrifuging at $5000 \mathrm{~g}$ for $25 \mathrm{~min}$ at $4{ }^{\circ} \mathrm{C}$ (Sorvall Biofuge fresco), and filtrated through an ultrafiltration tube (Millipore, Bedford, USA). Each $20 \mu \mathrm{L}$ sample of the diencephalon as well as a $10 \mu \mathrm{L}$ sample of the plasma was then dried under reduced pressure. The dried residues were dissolved in $10 \mu \mathrm{L}$ of $1 \mathrm{M}$ sodium acetatemethanol-triethylamine (2:2:1), and re-dried under reduced pressure, then dissolved in $20 \mu \mathrm{L}$ of methanol-distilled water-triethlaminephenylisothiocyanate $(7: 1: 1: 1)$ which was a derivatization solution. After phenylisocynate finished reacting with amino groups at room temperature for $20 \mathrm{~min}$ the samples were dried again and dissolved in $200 \mu \mathrm{L}$ of Pico-Tag Diluent (Waters, Milford, USA). These diluted samples were filtered through a $0.20 \mu \mathrm{m}$ filter (Millipore). The same methods were applied to standard solutions prepared by diluting a commercially available L-amino acid solution (type ANII, type B, Lasparagine, L-glutamine and L-tryptophan; Wako, Osaka, Japan) with distilled water. The derivatized samples and standard solutions were applied to a Waters HPLC system (Pico-Tag free amino acid analysis column (3.9 mm $\times 300 \mathrm{~mm}$ ), Alliance 2690 separation module, 2487 dual-wavelength UV detector, and Millennium 32 chromatography manager; Waters). They were equilibrated with buffer A (70 mM sodium acetate (pH 6.45 with 10\% acetic acid), acetonitrile (975:25)) and eluted with a linear gradient of buffer B (water-acetonitrile-methanol $(40: 45: 15)(0,3,6,9,40$, and $100 \%))$ at a flow rate of $1 \mathrm{~mL} / \mathrm{min}$ at $46{ }^{\circ} \mathrm{C}$. The concentrations of free amino acids were determined by absorbance at $254 \mathrm{~nm}$. Free amino acid concentrations in the diencephalon were expressed as $\mathrm{pmol} / \mathrm{mg}$ wet tissue and the plasma amino acid concentrations were expressed as $\mathrm{pmol} / \mu \mathrm{L}$.

\subsection{Statistical analysis}

Data were analyzed by factorial two-way analysis of variance (ANOVA) with respect to treatment (CT and HT) and time. Post-hoc comparisons were made between treatments at each time and between times for each treatment using Bonferroni tests. Statements of significance were based on $P<0.05$. Data were expressed as mean \pm S.E.M.

\section{Results}

\subsection{Rectal temperature, food intake and body mass in HT and CT chicks}

Rectal temperature, food intake and body mass of CT and HT chicks after 24- or 48-h are shown in Fig. 2. There was a significant effect of treatment $(P<0.05)$, no effect of time and no interaction of treatment and time for rectal temperature. Rectal temperature did not differ between chicks in the CT and HT groups after $24 \mathrm{~h}$ of treatment, whereas rectal temperatures were significantly higher in HT compared with CT chicks after $48 \mathrm{~h}(P<0.05)$. There was a significant effect of treatment $(P<0.05)$ and a significant effect of time $(P<0.001)$ on food intake, with no interaction of treatment and time. There were significant effects of treatment $(P<0.05)$ and time $(P<0.001)$, and no interaction of treatment and time for body mass. Body mass was greater at $48 \mathrm{~h}$ compared with $24 \mathrm{~h}$ for chicks in the control group $(P<0.001)$. Body mass did not differ between chicks in the CT and HT groups after $24 \mathrm{~h}$ of treatment, whereas body masses were significantly higher in CT compared with HT chicks after $48 \mathrm{~h}(P<0.05)$.

\subsection{Brain tissue oxidative damage}

To study oxidative damage to brain tissue in HT exposed chicks MDA, an oxidative stress biomarker for peroxidized lipids, was measured. Exposure to high temperature did not alter the MDA concentrations in the telencephalon and cerebellum (data not shown) of HT compared with control chicks. Concentrations of MDA in the diencephalon of CT and HT chicks after 24- or 48-h are shown in Fig. 3. There were significant effects of treatment $(P<0.01)$, and time $(P<0.001)$ on diencephalic MDA concentrations, and a significant interaction of treatment and time $(P<0.01)$, implying that the effect of the HT became more prominent with the progress of time. MDA concentrations were greater at $48 \mathrm{~h}$ in the HT chicks compared with $24 \mathrm{~h}$ HT and $48 \mathrm{~h}$ CT groups $(P<0.001)$. MDA concentrations did not differ between $24 \mathrm{~h} \mathrm{CT}$ and HT groups. In the mesencephalon, although treatment and time did not affect MDA concentrations $(P>0.05)$, there was an interaction between treatment and time $(P<0.05)$ (data not shown).

\subsection{Amino acid concentration in the diencephalon}

Concentrations of 26 free amino acids were measured in the diencephalon, with significant effects of treatment or time found for 8 amino acids (see Fig. 4 and Table 1). Fig. 4 shows the changes of amino acid concentrations affected by the treatment, time or interaction of treatment and time. Table 1 show the list of amino acids changed by the time or the interaction of treatment and time. There were effects of treatment on cystathionine, serine, tyrosine and isoleucine concentrations, and effects of time on serine, glycine, glutamine and lysine. Cystathionine was lower in HT birds compared with CT birds at $24 \mathrm{~h}$, whilst serine, tyrosine and isoleucine were higher at $48 \mathrm{~h}$ in HT birds. Posthoc comparisons were however not significant for any of these comparisons between HT and CT birds. Similarly, although serine, glutamine and lysine were lower at $48 \mathrm{~h}$ than $24 \mathrm{~h}$ in both groups, posthoc comparisons between times for HT and for CT were not significant.

\subsection{Free amino acid concentrations in the plasma}

Concentrations of 26 free amino acids were measured in the plasma, with significant treatment or time found for 8 amino acids (see Table 2). Cystathionine, cysteine, tryptophan, ornithine and citrulline were significantly $(P<0.05)$ lower in the HT chicks compared to CT chicks, while serine was higher $(P<0.05)$ in the HT chicks. In addition, GABA and taurine were significantly $(P<0.05)$ increased by time.

\section{Discussion}

The current study is the first to investigate the effects of high ambient temperature on lipid peroxidation and amino acid concentrations in the brains of young chicks. Chicks exposed to $35^{\circ} \mathrm{C}$ for $48 \mathrm{~h}$ had higher diencephalic concentrations of malondialdehyde (MDA; a marker of lipid peroxidation and oxidative stress) than control chicks, whereas there were no effects of high temperature on MDA concentrations in the mesencephalon, telencephalon or cerebellum. Exposure to high temperatures affected diencephalic concentrations of free amino acids. The high temperatures increased rectal temperatures and reduced food intake and hence reduced growth rate in the chicks, as expected from previous studies.

It is challenging for birds to maintain body temperature during HT as they lack sweat glands, relying on evaporative cooling (panting) to keep them cool (Marder and Arad, 1989; Ensminger et al., 1990). There are several reports (Deyhim and Teeter, 1991; Berrong and Washburn, 1998; Cooper and Washburn, 1998) of increased body temperature in adult chickens during heat stress. In the current study, rectal 

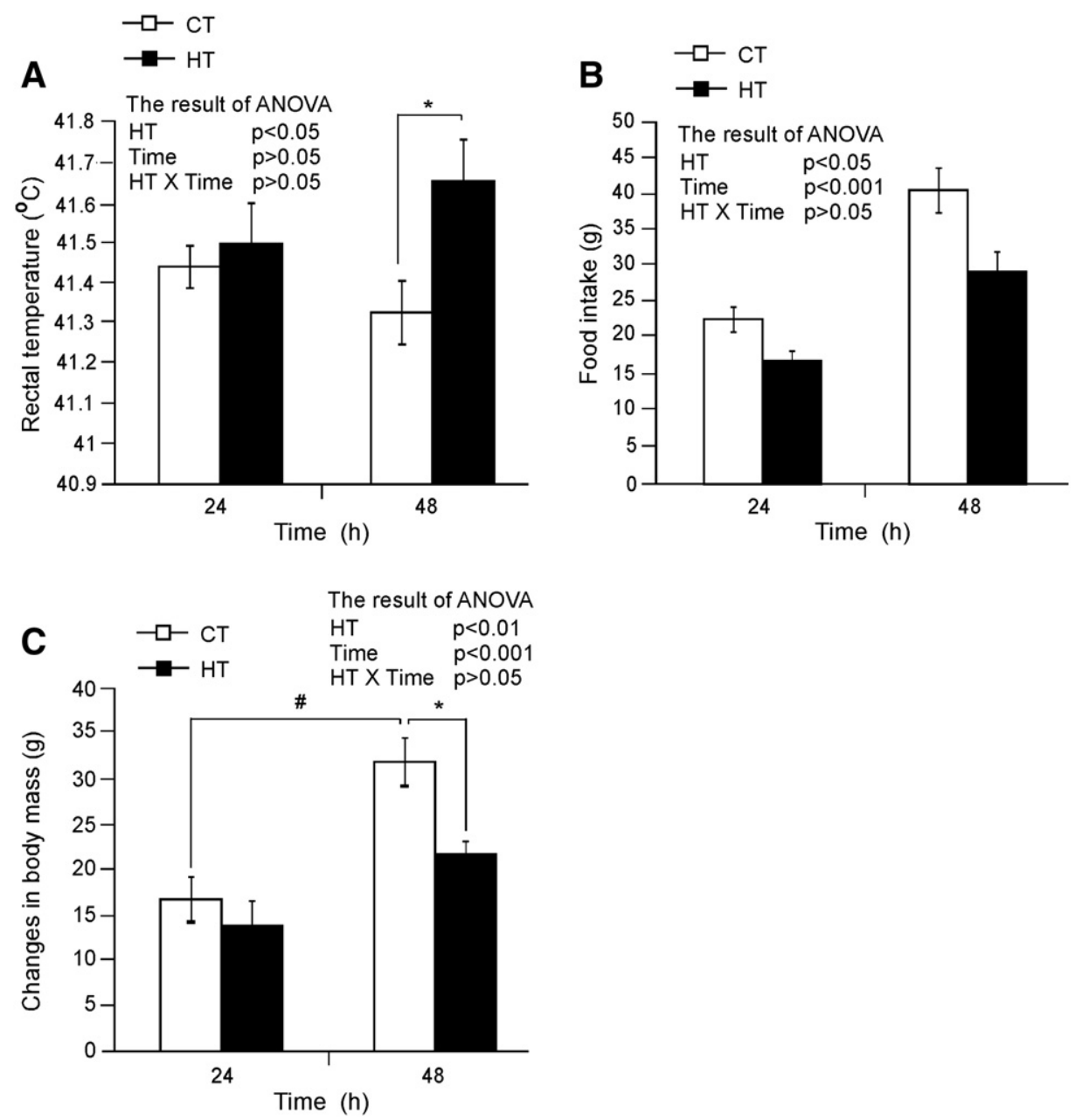

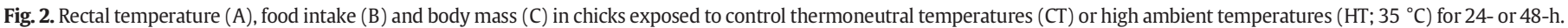
Values are mean \pm SEM of 7 chicks in each group.

temperature was also significantly increased by HT, indicating that thermoregulatory mechanisms to increase sensible heat loss in the chicks were not able to cope with the experimental higher temperature. One of the primary effects of HT on poultry is a reduction of food intake (Suk and Washburn, 1995; Chowdhury et al., 2012a,b; Song et al.,

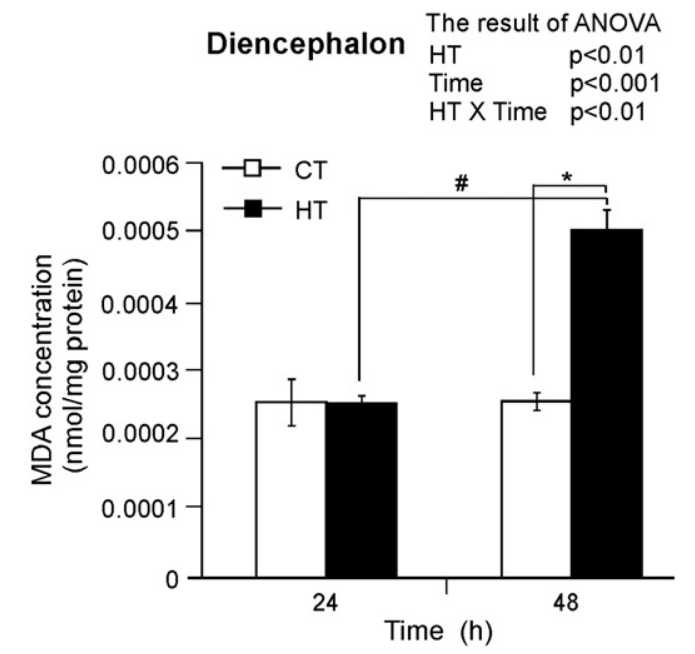

Fig. 3. Malondialdehyde (MDA) levels in the diencephalon of young chicks exposed to either control or high ambient temperature (HT; $35^{\circ} \mathrm{C}, 24-$ or 48 -h $)$. Values are mean \pm SEM of 7 chicks.
2012). Energy demands in poultry rise in temperatures above the upper critical temperature as active cooling mechanisms are activated. At the same time, birds reduce food intake to minimize excess metabolic energy production to keep them cool (Song et al., 2012). Appetite has been shown to decrease in chickens at elevated temperatures, followed by reductions in food intake and body weight (Rozenboim et al., 2004). In the present study, we also found that HT decreased food intake which affected the weight gain in chicks at an early stage of life.

Heat stress increased lipid peroxidation in the diencephalon of young chicks at $48 \mathrm{~h}$. The increased MDA concentrations at $48 \mathrm{~h}$ indicate increased free radical generation and oxidative damage in the diencephalon at $48 \mathrm{~h}$, whereas this was not apparent after $24 \mathrm{~h}$ of HT. Heat stress is one of the environmental stressors demonstrated to cause an increase in oxidative stress and an imbalance in antioxidant status (Gursu et al., 2004; Azad et al., 2013). It is known that superfluous reactive oxygen species induced by heat stress can cause oxidative injury, such as lipid peroxidation and oxidative damage to proteins and DNA (Mujahid et al., 2007). The chick brain is a very susceptible part of the body which is prone to oxidative stress when exposed to cold environmental temperature (Mujahid and Furuse, 2009b). However, to our knowledge, there is no report available on HT induced oxidative stress in the brain in chickens. Moreover, the part of the brain which is more susceptible to heat stress induced oxidative stress was also unknown. The current study is the first to show increased concentrations of MDA in the diencephalon (which includes thalamus and hypothalamus) after $48 \mathrm{~h}$ of HT exposure. Although it is not yet clear why the diencephalon showed the oxidative damage after $48 \mathrm{~h}$ of HT exposure whereas 

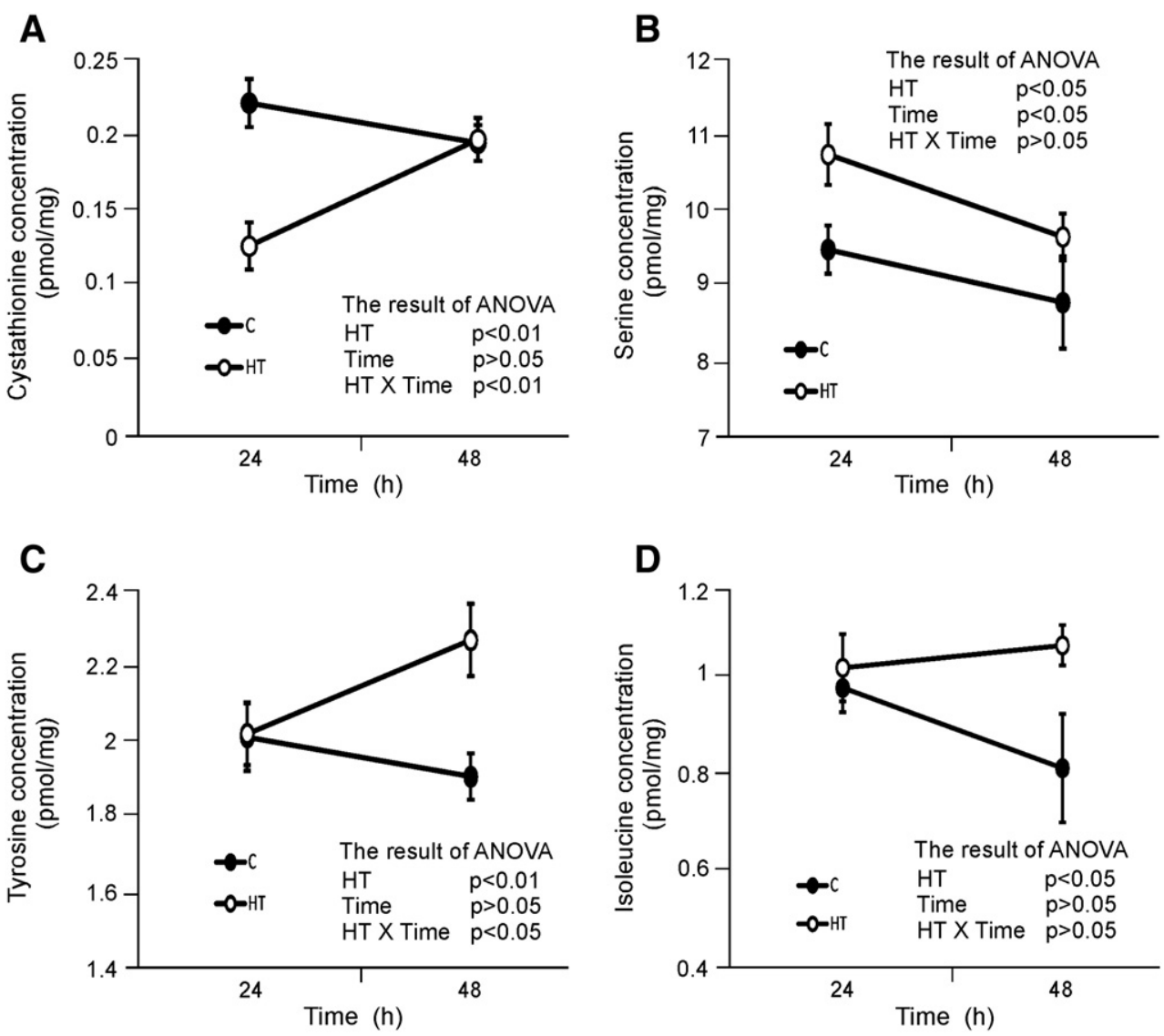

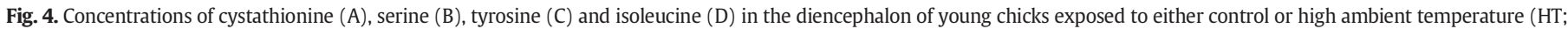
$35^{\circ} \mathrm{C}, 24$ - or 48 -h). Values are means \pm S.E.M of 7 chicks.

there were no effects in the telencephalon, mesencephalon or cerebellum, we could speculate that hypothalamus would be susceptible to heat. Heat receptors are thought to be located in the preoptic hypothalamus (Bligh, 1966; Yamamoto, 1999; Romanovsky, 2007). Thus, this part of the brain could be affected more during the exposure to heat which could lead to behavioral responses as the diencephalon contains several neurohormones that affect behavior. For instance, food intake regulation would be hampered during heat stress as hypothalamic neuropeptides such as neuropeptide Y (NPY) and gonadotropin-inhibitory hormone $(\mathrm{GnIH})$ play significant roles in food intake (Furuse, 2002; Boswell, 2005; Chowdhury et al., 2012).

There are interrelationships between nutritional status and resistance to acute heat stress in chickens (McCormick et al., 1979; Garlich and McCormick, 1981; Panda et al., 2008). Rhoads et al. (2013) suggested that heat stress caused shifting of energy metabolism from lipids to carbohydrate. However, amino acid metabolism during HT remains unknown. Therefore, free amino acid concentrations were measured in the diencephalon, a part of the brain that showed strong oxidative damage after $48 \mathrm{~h}$ of HT, and plasma. Twenty-six free amino acids were analyzed, of which eight amino acids of either similar or different type showed changes in the diencephalon and plasma during HT. Cystathionine was lower after $24 \mathrm{~h}$ but not $48 \mathrm{~h}$ of HT treatment compared to control birds, whilst tyrosine and isoleucine had increased after $48 \mathrm{~h}$ of HT and serine had higher level in both $24 \mathrm{~h}$ and $48 \mathrm{~h}$ of HT chicks. There were also some effects of time on glycine, glutamine, taurine and lysine. In the plasma, cystathionine, cysteine, tryptophan, ornithine and citrulline were lower in both $24 \mathrm{~h}$ and $48 \mathrm{~h}$, while serine was higher. Further work is needed to confirm in more detail patterns of amino acid metabolism in the diencephalons and plasma of chicks experiencing heat stress. We can nonetheless speculate on the basis of the observed changes in diencephalic and plasma free amino acids during HT. Cystathionine is synthesised from serine and homocysteine in a reaction catalyzed by cystathionine $\beta$-synthase, and is cleaved to cysteine by cystathionine $\gamma$-lyase (Fig. 5; Aitken et al., 2011; Yamada et al., 2012). It has been reported that homocysteine can induce oxidative stress in the brain (Matte et al., 2009). Stress also affects free amino acid

Table 1

Concentrations of free amino acids in the diencephalon of chicks that were exposed to HT or CT for 24- or 48-h.

\begin{tabular}{|c|c|c|c|c|c|c|c|}
\hline \multirow[b]{2}{*}{ Amino acids } & \multicolumn{2}{|l|}{$\mathrm{CT}$} & \multicolumn{2}{|l|}{ HT } & \multicolumn{3}{|l|}{$P$ value } \\
\hline & $24 \mathrm{~h}$ & $48 \mathrm{~h}$ & $24 \mathrm{~h}$ & $48 \mathrm{~h}$ & Treatment & Time & Treatment $\times$ Time \\
\hline Glycine & $22.1 \pm 0.7$ & $20.2 \pm 0.3$ & $21.4 \pm 0.4$ & $20.9 \pm 0.1$ & NS & $P<0.05$ & NS \\
\hline Glutamine & $75.7 \pm 3.3$ & $72.7 \pm 2.1$ & $69.6 \pm 2.1$ & $67.3 \pm 1.7$ & NS & $P<0.05$ & NS \\
\hline Taurine & $34.1 \pm 1.1$ & $31.5 \pm 1.0$ & $32.4 \pm 0.6$ & $33.8 \pm 0.4$ & NS & NS & $P<0.05$ \\
\hline Lysine & $3.9 \pm 0.6$ & $2.9 \pm 0.3$ & $5.4 \pm 1.2$ & $3.6 \pm 0.5$ & NS & $P<0.05$ & NS \\
\hline
\end{tabular}

Values are means \pm S.E.M. in pmol/mg; $n=7$ in each group; NS: Not significant. 
Table 2

Concentrations of free amino acids in the plasma of chicks that were exposed to HT or CT for 24- or 48-h.

\begin{tabular}{|c|c|c|c|c|c|c|c|}
\hline \multirow[b]{2}{*}{ Amino acids } & \multicolumn{2}{|l|}{$\mathrm{CT}$} & \multicolumn{2}{|l|}{ HT } & \multicolumn{3}{|l|}{$P$ value } \\
\hline & $24 \mathrm{~h}$ & $48 \mathrm{~h}$ & $24 \mathrm{~h}$ & $48 \mathrm{~h}$ & Treatment & Time & Treatment $\times$ Time \\
\hline Cystathionine & $18.5 \pm 1.0$ & $16.7 \pm 1.2$ & $13.3 \pm 1.2$ & $11.2 \pm 1.0$ & $P<0.001$ & NS & NS \\
\hline Serine & $793.0 \pm 58.1$ & $878.4 \pm 48.2$ & $1065.5 \pm 41.9$ & $1003.5 \pm 141.6$ & $P<0.05$ & NS & NS \\
\hline Cystine & $48.7 \pm 6.3$ & $47.4 \pm 3.7$ & $39.8 \pm 2.8$ & $31.4 \pm 5.8$ & $P<0.05$ & NS & NS \\
\hline Tryptophan & $14.5 \pm 1.8$ & $17.1 \pm 1.0$ & $13.8 \pm 1.0$ & $12.9 \pm 1.0$ & $P<0.05$ & NS & NS \\
\hline Ornithine & $142.8 \pm 24.6$ & $110.4 \pm 7.1$ & $100.4 \pm 9.0$ & $69.4 \pm 7.7$ & $P<0.05$ & $P<0.05$ & NS \\
\hline Citrulline & $35.4 \pm 3.9$ & $32.2 \pm 3.3$ & $26.6 \pm 4.4$ & $18.9 \pm 3.0$ & $P<0.05$ & NS & NS \\
\hline GABA & $42.5 \pm 3.7$ & $82.6 \pm 11.3$ & $63.6 \pm 6.8$ & $89.7 \pm 12.6$ & NS & $P<0.05$ & NS \\
\hline Taurine & $127.0 \pm 4.7$ & $307.7 \pm 24.2$ & $223.1 \pm 36.8$ & $328.5 \pm 38.5$ & NS & $P<0.05$ & NS \\
\hline
\end{tabular}

Values are means \pm S.E.M. in pmol/ $\mu \mathrm{L} ; n=7$ in each group; NS: Not significant.

metabolism in the rat brain. Nagasawa et al. (2012) reported that several free amino acids altered in the stress sensitive rat brain, with special reference to lower cystathionine and serine levels. Thus, it could be suggested that homocysteine could be engaged to trigger oxidative stress in the brain and as a result serine increased and cystatheonine declined at $24 \mathrm{~h} \mathrm{HT}$ in the current study. However, we found that cystathionine increased to the level of control birds at $48 \mathrm{~h}$ of HT. It has been reported that cystathionine $\beta$-synthase expression increased in the mouse brain to protect it after traumatic injury (Zhang et al., 2013). The expression of the enzyme cystathionine $\beta$-synthase and hence cystathionine might have increased to protect the brain against oxidative damage at $48 \mathrm{~h}$ of HT. In contrast, plasma cystathionine showed lower levels both at $24 \mathrm{~h}$ and $48 \mathrm{~h}$ of HT that also might have led to the lower plasma cysteine level in the current study. Plasma serine showed higher concentrations in HT chicks, which were similar pattern in changing with diencephalic amino acids, indicate that plasma homocysteine might be altered. Tyrosine, an aromatic amino acid, is a precursor in dopamine synthesis and dopamine is also the precursor to norepinephrine. Tyrosine increased dopamine and norepinephrine (monoamines) turnover rates and effectively ameliorated signs of hyperactivity (Kabuki et al., 2011). The increased diencephalic tyrosine in the current study might be related to a role of catecholaminergic pathways during the response of chicks to HT. In addition, change in plasma differed from changes in the diencephalon for some amino acids. For instance, amino acids of the urea cycle, namely ornithine and citrulline declined in the plasma of HT chicks whereas they did not change in the diencephalon. In the present study, chicks exposed to HT for 24- and 48-h would have experienced changes in amino acid metabolism as a consequence of reduced food intake. However, a short exposure of chicks to HT such as 15- or 30min did not decrease food intake, but modified amino acid concentration in chicks (Ito et al., unpublished data), and we conclude that changes in amino acids in HT chicks were due at least in part to direct effects of HT. Further study is needed to clarify the physiological significance of the alteration of amino acid metabolisms in heat-exposed chicks.

In conclusion, $48 \mathrm{~h}$ of $\mathrm{HT}$ increased rectal temperature, reduced food intake and reduced body weight in young chicks. HT increased diencephalic oxidative damage and altered some free amino acid concentrations in the diencephalon and plasma. Our results suggest that the alteration in amino acid metabolism during HT may contribute to the induction of oxidative damage in the chick brain.

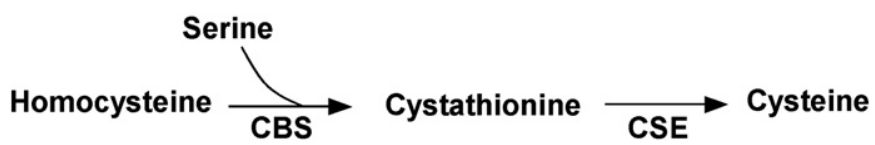

Fig. 5. Metabolic pathway of cystathionine, serine and homocysteine. Cystathionine is synthesized from serine and homocysteine by cystathionine $\beta$-synthase (CBS, EC 4.2.1.22) and metabolized to cysteine by cystathionine $\gamma$-lyase (CSE, EC 4.4.1.1).

\section{Disclosure}

The authors of this manuscript have nothing to declare.

\section{Acknowledgments}

This work was supported by a start-up fund support for Scientific Research from MEXT G30 project through Kyushu University, Japan (JA79989023) to VSC and a Grant-in-Aid for Scientific Research from the Japan Society for the Promotion of Science (21380165) to MF.

\section{References}

Aitken, S.M., Lodha, P.H., Morneau, D.J., 2011. The enzymes of the transsulfuration pathways: active-site characterizations. Biochim. Biophys. Acta 1814, 1511-1517.

Ajakaiye, J.J., Ayo, J.O., Ojo, S.A., 2010. Effects of heat stress on some blood parameters and egg production of Shika Brown layer chickens transported by road. Biol. Res. 43, $183-1189$.

Azad, M.A., Kikusato, M., Maekawa, T., Shirakawa, H., Toyomizu, M., 2010a. Metabolic characteristics and oxidative damage to skeletal muscle in broiler chickens exposed to chronic heat stress. Comp. Biochem. Physiol. A Mol. Integr. Physiol. 155, 401-406.

Azad, M.A., Kikusato, M., Sudo, S. Amo, T., Toyomizu, M., 2010b. Time course of ROS production in skeletal muscle mitochondria from chronic heat-exposed broiler chicken. Comp. Biochem. Physiol. A Mol. Integr. Physiol. 157, 266-271.

Azad, M.A., Kikusato, M., Zulkifli, I., Toyomizu, M., 2013. Electrolysed reduced water decreases reactive oxygen species-induced oxidative damage to skeletal muscle and improves performance in broiler chickens exposed to medium-term chronic heat stress. Br. Poult. Sci. 54, 503-509.

Bartlett, J.R., Smith, M.O., 2003. Effects of different levels of zinc on the performance and immunocompetence of broilers under heat stress. Poult. Sci. 82, 1580-1588.

Bast, A., Goris, R.J.A., 1989. Oxidative stress. Biochemistry and human disease. Pharm. Weekbl. Sci. 11, 199-206.

Berrong, S.L., Washburn, K.W., 1998. Effects of genetic variation on total plasma protein, body weight gains, and body temperature responses to heat stress. Poult. Sci. 77, 379-385.

Bhutia, Y., Ghosh, A., Sherpa, M.L., Pal, R., Mohanta, P.K., 2011. Serum malondialdehyde level: surrogate stress marker in the Sikkimese diabetics. J. Nat. Sci. Biol. Med. 2, $107-112$.

Bhuyan, K.C., Bhuyan, D.K., Podos, S.M., 1986. Lipid peroxidation in cataract of the human. Life Sci. 38, 1463-1471.

Bligh, J., 1966. The thermosensitivity of the hypothalamus and thermoregulation in mammals. Biol. Rev. 41, 317-368.

Boogers, I., Plugge, W., Stokkermans, Y.Q., Duchateau, A.L., 2008. Ultra-performance liquid chromatographic analysis of amino acids in protein hydrolysates using an automated pre-column derivatisation method. J. Chromatogr. A 1189, 406-409.

Boswell, T., 2005. Regulation of energy balance in birds by the neuroendocrine hypothalamus. J. Poult. Sci. 42, 161-181.

Chowdhury, V.S., Tomonaga, S., Nishimura, S., Tabata, S., Cockrem, J.F., Tsutsui, K., Furuse, M., 2012a. Hypothalamic gonadotropin-inhibitory hormone precursor mRNA is increased during depressed food intake in heat-exposed chicks. Comp. Biochem. Physiol. A Mol. Integr. Physiol. 162, 227-233.

Chowdhury, V.S., Tomonaga, S., Nishimura, S., Tabata, S., Furuse, M., 2012b. Physiological and behavioral responses of young chicks to high ambient temperature. J. Poult. Sci. 49, 212-218.

Cooper, M.A., Washburn, K.W., 1998. The relationships of body temperature to weight gain, feed consumption, and feed utilization in broilers under heat stress. Poult. Sci. 77, 237-242.

Deyhim, F., Teeter, R.G., 1991. Research note: sodium and potassium chloride drinking water supplementation effects on acid-base balance and plasma corticosterone in broilers reared in thermoneutral and heat-distressed environments. Poult. Sci. 70, 2551-2553. 
Ensminger, M.E., Oldfield, J.E., Heinemann, W.W., 1990. Feeds and Nutrition. The Ensminger Publishing Company, Clovis, CA.

Erwan, E., Tomonaga, S., Yoshida, J., Nagasawa, M., Ogino, Y., Denbow, D.M., Furuse, M., 2012. Central administration of L- and D-aspartate attenuates stress behaviors by social isolation and CRF in neonatal chicks. Amino Acids 43, 1969-1976.

Etches, R., John, J.M., Gibbins, A.M.V., 1995. Behavioural, physiological, endocrine and molecular responses to heat stress. In: Daghir, N.J. (Ed.), Poultry Production in Hot Climates. CAB International, Wallingford, pp. 31-65.

Franco-Jimenez, D.J., Beck, M.M., 2007. Physiological changes to transient exposure to heat stress observed in laying hens. Poult. Sci. 86, 538-544.

Furuse, M., 2002. Central regulation of food intake in the neonatal chick. Anim. Sci. J. 73, 83-94.

Garlich, J.D., McCormick, C.C., 1981. Interrelationships between environmental temperature and nutritional status of chicks. Fed. Proc. 40, 73-76.

Gursu, M.F., Onderci, M., Gulcu, F., Sahin, K., 2004. Effects of vitamin C and folic acid supplementation on serum paraoxonase activity and metabolites induced by heat stress in vivo. Nutr. Res. 24, 157-164.

Hamasu, K., Haraguchi, T., Kabuki, Y., Adachi, N., Tomonaga, S., Sato, H., Denbow, D.M., Furuse, M., 2009. L-proline is a sedative regulator of acute stress in the brain of neonatal chicks. Amino Acids 37, 377-382.

Hamasu, K., Shigemi, K., Tsuneyoshi, Y., Yamane, H., Sato, H., Denbow, D.M., Furuse, M., 2010. Intracerebroventricular injection of L-proline and D-proline induces sedative and hypnotic effects by different mechanisms under an acute stressful condition in chicks. Amino Acids 38, 57-64.

Howlider, M.A.R., Rose, S.P., 1987. Temperature and the growth of broilers. World's Poult. Sci. J. 43, 228-237.

Hurwitz, S., Weiselberg, M., Eisner, U., Bartov, I., Riesenfeld, G., Sharvit, M., Niv, A., Bornstein, S., 1980. The energy requirements and performance of growing chickens and turkeys as affected by environmental temperature. Poult. Sci. 59, 2290-2299.

Iwagami, Y., 1996. Changes in the ultrasonic of human cells related to certain biological responses under hyperthermic culture conditions. Hum. Cell 9, 353-366.

Jones, D.P., 2006. Redefining oxidative stress. Antioxid. Redox Signal. 8, 1865-1879.

Kabuki, Y., Shigemi, K., Hamasu, K., Denbow, D.M., Furuse, M., 2011. Chronic L-tyrosine alters the locomotor activity and brain monoamine levels in Roborovskii hamsters. Neurosci. Lett. 488, 45-48.

Kuenzel, W., Masson, M., 1988. A Stereotaxic Atlas of the Brain of the Chick (Gallus domesticus). The Johns Hopkins University Press, Baltimore and London 143-153.

Likidlilid, A., Patchanans, N., Peerapatdit, T., Sriratanasathavorn, C., 2010. Lipid peroxidation and antioxidant enzyme activities in erythrocytes of type 2 diabetic patients. J. Med. Assoc. Thai. 93, 682-693.

Lin, H., Du, R., Zhang, Z.Y., 2000. Peroxide status in tissues of heat-stressed broilers. AsianAust. J. Anim. Sci. 13, 1373-1376.

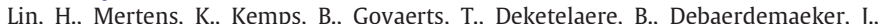
Decuypere, E., Buyse, J., 2004. New approach of testing the effect of heat stress on egg quality: mechanical and material properties of eggshell and membrane. Br. Poult. Sci. 45, 476-482.

Lin, H., Decuypere, E., Buyse, J., 2006. Acute heat stress induces oxidative stress in broiler chickens. Comp. Biochem. Physiol. A Mol. Integr. Physiol. 144, 11-17.

Marder, J., Arad, Z., 1989. Panting and acid-base regulation in heat stressed birds. Comp. Biochem. Physiol. A Comp. Physiol. 94, 395-400.

Marsden, A., Morris, T.R., Cromarty, A.S., 1987. Effects of constant environmental temperatures on the performance of laying pullets. Br. Poult. Sci. 28, 361-380.

Mashaly, M.M., Hendricks, G.L., Kalama, M.A., Gehad, A.E., Abbas, A.O., Patterson, P.H., 2004. Effect of heat stress on production parameters and immune responses of commercial laying hens. Poult. Sci. 83, 889-894.

Matte, C., Stefanello, F.M., Mackedanz, V., Pederzolli, C.D., Lamers, M.L., Dutra-Filho, C.S. Dos Santos, M.F., Wyse, A.T., 2009. Homocysteine induces oxidative stress, inflammatory infiltration, fibrosis and reduces glycogen/glycoprotein content in liver of rats. Int. J. Dev. Neurosci. 27, 337-344.

McCormick, C.C., Garlich, J.D., Edens, F.W., 1979. Fasting and diet affect the tolerance of young chickens exposed to acute heat stress. J. Nutr. 109, 1797-1809.

Mujahid, A., Furuse, M., 2009. Oxidative damage in different tissues of neonatal chicks exposed to low environmental temperature. Comp. Biochem. Physiol. A Mol. Integr. Physiol. 152, 604-608.
Mujahid, A., Akiba, Y., Toyomizu, M., 2007. Acute heat stress induces oxidative stress and decreases adaptation in young white leghorn cockerels by down regulation of avian uncoupling protein. Poult. Sci. 86, 364-371.

Mujahid, A., Akiba, Y., Toyomizu, M., 2009. Olive oil supplemented diet alleviates acute heat stress-induced mitochondrial ROS production in chicken skeletal muscle. Am. J. Physiol. Regul. Integr. Comp. Physiol. 297, R690-R698.

Nagasawa, M., Murakami, T., Tomonaga, S., Furuse, M., 2012. The impact of chronic imipramine treatment on amino acid concentrations in the hippocampus of mice. Nutr. Neurosci. 15, 26-33.

Niu, Z., Liu, F., Yan, Q., Li, L., 2009. Effects of different levels of selenium on growth performance and immunocompetence of broilers under heat stress. Arch. Anim. Nutr. 63 56-65.

Panda, A.K., Ramarao, S.V., Raju, M.V., Chatterjee, R.N., 2008. Effect of dietary supplementation with vitamins $\mathrm{E}$ and $\mathrm{C}$ on production performance, immune responses and antioxidant status of White Leghorn layers under tropical summer conditions. Br. Poult Sci. 49, 592-599.

Peguri, A., Coon, C., 1991. Effect of temperature and dietary energy on layer performance Poult. Sci. 70, 126-138.

Rhoads, R.P., Baumgard, L.H., Suagee, J.K., Sanders, S.R., 2013. Nutritional interventions to alleviate the negative consequences of heat stress. Adv. Nutr. 4, 267-276.

Romanovsky, A.A., 2007. Thermoregulation: some concepts have changed. Functional architecture of the thermoregulatory system. Am. J. Physiol. Regul. Integr. Comp. Physiol. 292, R37-R46.

Rozenboim, I., Mobarky, N., Heiblum, R., Chaiseha, Y., Kang, S.W., Biran, I., Rosenstrauch, A., Sklan, D., El Halawani, M.E., 2004. The role of prolactin in reproductive failure associated with heat stress in the domestic turkey. Biol. Reprod. 71, 1208-1213.

Satoh, K., 1978. Serum lipid peroxide in cerebrovascular disorders determined by a new colorimetric method. Clin. Chim. Acta 90, 37-43.

Savory, J.C., 1986. Influence of ambient temperature on feeding activity parameters and digestive function in domestic fowls. Physiol. Behav. 38, 353-357.

Siegel, H.S., 1995. Stress, strains and resistance. Br. Poult. Sci. 36, 3-20.

Soleimani, A.F., Kasim, A., Alimon, A.R., Meimandipour, A., Zulkifli, I., 2010. Ileal endogenous amino acid flow of broiler chickens under high ambient temperature. J. Anim. Physiol. Anim. Nutr. (Berl) 94, 641-647.

Song, Z., Liu, L., Sheikhahmadi, A., Jiao, H., Lin, H., 2012. Effect of heat exposure on gene expression of feed intake regulatory peptides in laying hens. J. Biomed. Biotechnol. 2012, 1-8.

Sterling, K.G., Bell, D.D., Pesti, G.M., Aggrey, S.E., 2003. Relationships among strain, performance, and environmental, temperature in commercial laying hens. J. Appl. Poult. Res. 12, 85-91.

Suk, Y.O., Washburn, K.W., 1995. Effects of environment on growth, efficiency of feed utilization, carcass fatness, and their association. Poult. Sci. 74, 285-296.

Yagi, K., 1984. Assay for blood plasma or serum. Methods Enzymol. 105, 328-331.

Yahav, S., Hurwitz, S., 1996. Induction of thermotolerance in male broiler chickens by temperature conditioning at an early age. Poult. Sci. 75, 402-406.

Yahav, S., Shinder, D., Razpakovski, V., Rusal, M., Bar, A., 2000. Lack of response of laying hens to relative humidity at high ambient temperature. Br. Poult. Sci. 41, 660-663.

Yamada, H., Akahoshi, N., Kamata, S., Hagiya, Y., Hishiki, T., Nagahata, Y., Matsuura, T., Takano, N., Mori, M., Ishizaki, Y., Izumi, T., Kumagai, Y., Kasahara, T., Suematsu, M. Ishii, I., 2012. Methionine excess in diet induces acute lethal hepatitis in mice lacking cystathionine $\gamma$-lyase, an animal model of cystathioninuria. Free Radic. Biol. Med. 52, 1716-1726.

Yamamoto, S., 1999. Thermoregulation and environmental management in poultry production. The Text Book for Group Training Course in Poultry Production and Breeding Technology.Japan International Cooperation Agency (JICA), National Livestock Breeding Center, Japan.

Yamane, H., Asechi, M., Tsuneyoshi, Y., Kurauchi, I., Denbow, D.M., Furuse, M., 2009. Intracerebroventricular injection of L-aspartic acid and L-asparagine induces sedative effects under an acute stressful condition in neonatal chicks. Anim. Sci. J. 80, 286-290.

Yu, J., Bao, E., Yan, J., Lei, L., 2008. Expression and localization of Hsps in the heart and blood vessel of heat-stressed broilers. Cell Stress Chaperones 13, 327-335.

Zhang, M., Shan, H., Wang, Y., Wang, T., Liu, W., Wang, L., Zhang, L., Chang, P., Dong, W. Chen, X., Tao, L., 2013. The expression changes of cystathionine- $\beta$-synthase in brain cortex after traumatic brain injury. J. Mol. Neurosci. 51, 57-67. 